\title{
ASSESSMENT OF HYDROLOGIC ALTERATIONS CAUSED BY CHI-CHI DIVERSION WEIR IN CHOU-SHUI CREEK, TAIWAN: OPPORTUNITIES FOR RESTORING NATURAL FLOW CONDITIONS
}

\author{
JENQ-TZONG SHIAU ${ }^{\mathrm{a} *}$ and FU-CHUN WU \\ a Department of Water Resources and Environmental Engineering, Tamkang University, Tamsui 251, Taiwan, ROC \\ ${ }^{\mathrm{b}}$ Department of Bioenvironmental Systems Engineering and Hydrotech Research Institute, National Taiwan University, Taipei 106, \\ Taiwan, $R O C$
}

\begin{abstract}
The Range of Variability Approach (RVA) is used to investigate the hydrologic impacts of a diversion weir on Chou-Shui Creek, Taiwan. Thirty-two hydrologic parameters, called Indicators of Hydrologic Alteration (IHA), are used to evaluate the flow conditions before and after weir construction. One standard deviation from the mean for each of the pre-construction hydrologic parameters is set as the management target range. Under the prevailing diversion rules, large hydrologic alterations are observed, especially for low flows. The means of 19 hydrologic parameters presently fall outside of the targets and the average non-attainment rate for the 32 indicators is $73.2 \%$. Increasing the instream flow release or reducing diversions could mitigate the hydrologic impacts of weir construction. Increasing the instream flow to $40 \mathrm{~m}^{3} / \mathrm{s}$ and reducing monthly water demands by variable percentages significantly improves the altered flow conditions. Under the proposed water release and diversion scheme, 29 hydrologic parameters will fall within the management targets and the average non-attainment rate will be reduced to $35.6 \%$, much closer to the pre-construction value of $25.3 \%$. Restoring the natural flow variability is expected to promote the natural stream biota. Copyright (C) 2004 John Wiley \& Sons, Ltd.
\end{abstract}

KEY WORDS: Range of Variability Approach (RVA); Indicators of Hydrologic Alteration (IHA); instream flow

\section{INTRODUCTION}

The growing demand for municipal, industrial, and agricultural water has raised the need to construct hydraulic structures, such as reservoirs and weirs, over the past four decades in Taiwan. These structures facilitate water supplies but also alter the hydrologic regimes of rivers (Sale et al., 1982; Cardwell et al., 1996; Benjamin and VanKirk, 1999; Smith et al., 2000; Cowell and Scoudt, 2002; Flug et al., 2000). The impacts on aquatic environments have been extensively studied (e.g. Richter et al., 1997). Several instream flow methods based on the historical flow, hydraulic geometry and riverine habitat have been developed for assessing instream flow requirements (Jowett, 1997). The Physical Habitat Simulation (PHABSIM) model (Milhous et al., 1989) is one such model that incorporates a biological component, although the focus on merely one or a few target species is a shortcoming (Reiser et al., 1989). In fact, rather than the specific hydraulic conditions favourable to the target species, a full range of natural hydrologic regimes is a primary driving force in riverine ecosystems, and an essential factor in sustaining aquatic environments (NRC, 1992). Richter et al. (1997) developed the Range of Variability Approach (RVA) to establish flow-based river management targets that incorporate the concepts of hydrologic variability and aquatic ecosystem integrity. This method uses 32 hydrologic parameters (Indicators of Hydrologic Alteration, IHA) to assess alterations in terms of flow magnitude, timing, frequency, duration and rate of change (Richter et al., 1996). A natural range of variations in each parameter is set as the flow management target.

\footnotetext{
* Correspondence to: J.-T. Shiau, Department of Water Resources and Environmental Engineering, Tamkang University, Tamsui 251, Taiwan, ROC. E-mail: jtshiau@mail.tku.edu.tw
} 
The RVA is used in this study to evaluate the impacts of Chi-Chi diversion weir on the hydrologic regimes of midstream Chou-Shui Creek, Taiwan. Natural flow variations in the creek prior to and after weir construction are characterized, and a water release and diversion scheme is proposed to mitigate the hydrologic impacts.

\section{RANGE OF VARIABILITY APPROACH}

The RVA uses 32 IHA to evaluate the hydrologic alterations (Richter et al., 1997). These are categorized into five groups addressing the magnitude, timing, frequency, duration, and rate of change (Table I).

IHA Group 1. Twelve monthly mean flows describe the normal flow condition.

IHA Group 2. Ten parameters describe the magnitude and duration of annual extreme flows, including 1-, 3-, 7-, 30-, and 90-day annual maxima and minima encompassing the daily, weekly, monthly and seasonal cycles.

IHA Group 3. Julian dates for 1-day annual maximum and minimum indicate the timing of annual extreme flows.

IHA Group 4. Four parameters refer to the frequency and duration of high and low pulses. The high pulse is periods within a year when the daily flows are above the 75th percentile daily flow of the pre-impact time period. The low pulse is periods within a year when the daily flows are below the 25 th percentile daily flow of the pre-impact time period (Richter et al., 1996).

IHA Group 5. Four parameters (fall rate, rise rate, fall count, rise count) indicate the numbers and mean rates of both positive and negative changes of flow in two consecutive days.

Details are provided by Richter et al. (1996). The mean, standard deviation, and range for these parameters are computed with the pre-impact daily flows. In this study, the RVA target ranges for each parameter are bracketed by the mean value plus or minus one standard deviation, as suggested by Richter et al. (1997). Where the upper end of the target range is above the upper limit of observed pre-impact values, or the lower end of the target range is below the lower limit, the observed range limits can be used as the RVA targets instead. The management objective

Table I. Indicators of Hydrologic Alteration (IHA)

IHA group

Group 1: Magnitude of monthly water conditions

Group 2: Magnitude and duration of annual extreme conditions

Group 3: Timing of annual extreme water conditions

Group 4: Frequency and duration of high and low pulses

Group 5: Rate and frequency of water condition changes
Hydrologic parameters

Mean value for each calendar month
Annual minimum 1-day means
Annual maximum 1-day means
Annual minimum 3-day means
Annual maximum 3-day means
Annual minimum 7-day means
Annual maximum 7-day means
Annual minimum 30-day means
Annual maximum 30-day means
Annual minimum 90-day means
Annual maximum 90-day means
Julian date of each annual 1-day maximum
Julian date of each annual 1-day minimum
Number of high pulses each year
Number of low pulses each year
Mean duration of high pulses within each year
Mean duration of low pulses within each year
Means of all positive differences between consecutive daily
values
Means of all negative differences between
consecutive daily values
Number of rises
Number of falls


is thus to make post-construction flow regimes attain the RVA targets at the same frequency as occurred in the pre-construction period.

\section{CASE STUDY}

Chi-Chi diversion weir is on the midstream reach of Chou-Shui Creek, Central Taiwan (Figure 1). The creek is the longest river in Taiwan, $(187 \mathrm{~km})$ and has a catchment of $3157 \mathrm{~km}^{2}$ and average annual runoff about $6100 \mathrm{Mm}^{3}$. In 1984, the diversion weir was proposed to meet the increasing regional demand for water. Construction began in 1993 and was completed in 2001. The design capacity for diversion is $160 \mathrm{~m}^{3} / \mathrm{s}$.

Recorded daily flows at the Chi-Chi gauging station are for August 1950 to June 1994. Forty-three years of daily records, from January 1951 to December 1993, were used to evaluate the natural hydrologic variation prior to weir construction. Apparent seasonal variations are observed. The period between June and September is the high-flow season; the remaining months constitute the low-flow season. The weir storage capacity is not sufficient to regulate such highly fluctuating flows, and thus stable water supplies would be difficult.

The temporal distribution of projected demands is shown in Figure 2, which result in a total annual consumption of $3080 \mathrm{Mm}^{3}$ (Central Water Resources Bureau, 2002). The minimum instream flow to be released for downstream water-quality and environmental considerations is $0.6 \mathrm{~m}^{3} / \mathrm{s}$ (Wang and Lin, 1998). The water release priority for the Chi-Chi diversion weir is to meet the instream flow requirement first and then divert the remaining flow to other users.

The midstream reach of Chou-Shui Creek provided habitats for several endemic species, including Abbottina brevirostns, Acrossochilus paradoxus, Hemimyzon formosanum, and Sinogastromyzon puliensis, prior to the construction of Chi-Chi weir (TESRC, 1995). Sinogastromyzon puliensis was further claimed as one of the endangered species (TESCR, 1996). The pre-construction flow conditions are thus believed to provide a suitable reference for evaluating the impacts of weir construction. Wu and Lee (1998) indicated that the instream flow need for Chou-Shui Creek downstream of the Chi-Chi diversion weir is at least $40 \mathrm{~m}^{3} / \mathrm{s}$, evaluated with the hydrologic, hydraulic, and habit methods. The current instream flow release of $0.6 \mathrm{~m}^{3} / \mathrm{s}$, which was a rough estimate based on a Japanese empirical formula, is obviously inadequate. Therefore, the RVA is used in this study to evaluate the effects of different instream flow releases.

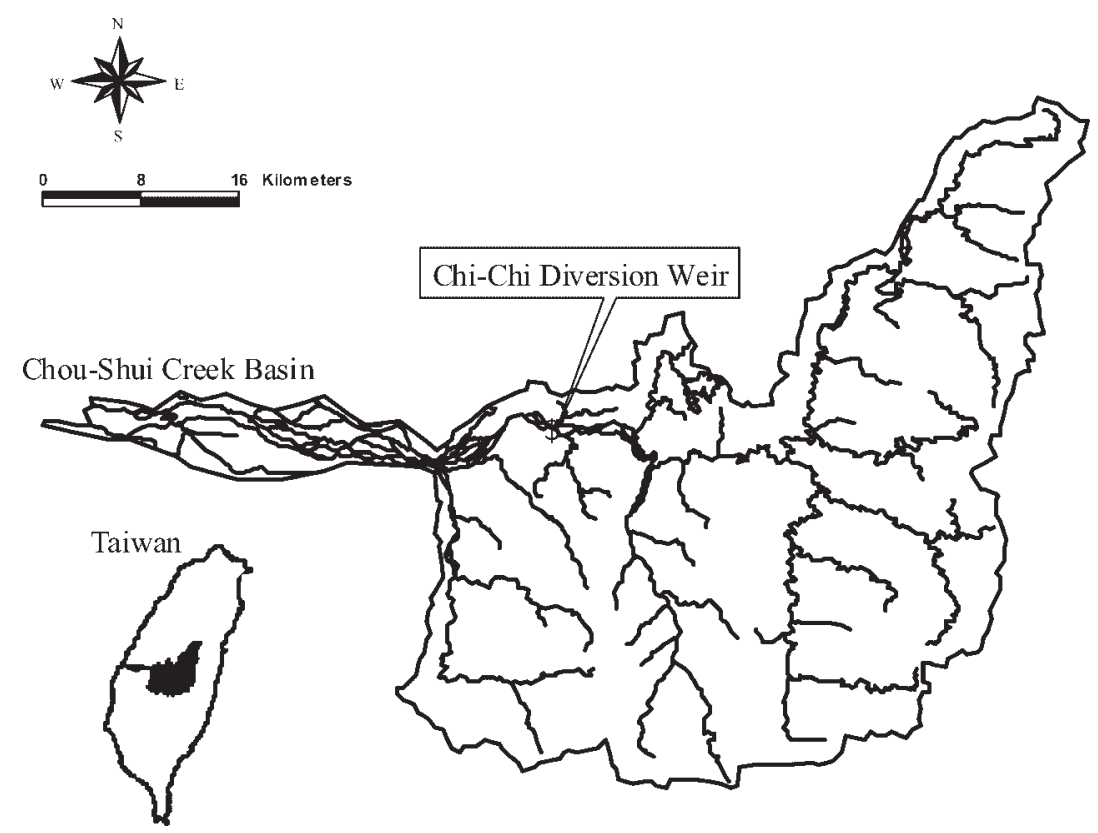

Figure 1. Location map of the Chou-Shui Creek Basin and Chi-Chi diversion weir 


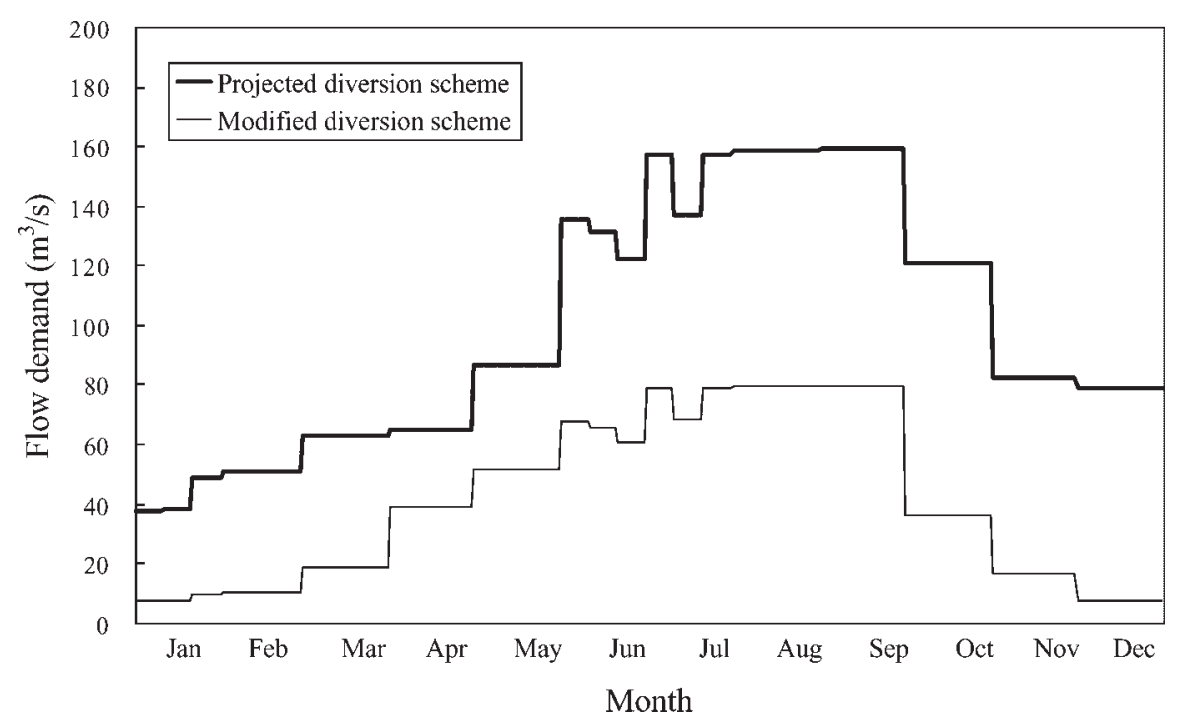

Figure 2. Projected and modified diversion schemes for the Chi-Chi diversion weir

\section{RESULTS AND DISCUSSION}

\section{Indicators of hydrologic alteration prior to weir construction}

The means, standard deviations, and ranges of 32 hydrologic parameters prior to weir construction are listed in Table II, where the RVA targets based on one standard deviation from mean for each parameter are also shown. The last column in Table II is the non-attainment rate for each IHA, defined as the percentage of time the hydrologic parameter is outside the RVA target ranges. The non-attainment rates for the pre-construction period ranged from 7.0 to $39.5 \%$, and the overall average non-attainment rate was $25.3 \%$. This phenomenon indicates that even the pre-construction flow regimes do not attain the RVA targets every year. As an example, the left-hand part of Figure 3 illustrates the monthly flows in October prior to the weir construction. A non-attainment rate of $25.6 \%$ in October indicates that more than a quarter of the pre-construction years fall outside the RVA target ranges.

The non-attainment rates of the monthly mean (IHA Group 1) for June to August are higher than those for the other months, primarily due to the greater flow fluctuations in June to August. The non-attainment rates of the annual 1-, 3-, 7-, and 30-day minima are higher than those of the annual 1-, 3-, 7-, and 30-day maxima (IHA Group 2), but reverse for the 90-day extremes. The non-attainment rate of the annual minimum Julian date is less than that of the annual maximum Julian date (IHA Group 3), indicating that the timing of annual maximum is more uncertain. The non-attainment rate of the high-pulse count (37.2\%) is greater than that of the low-pulse count (27.9\%), while the non-attainment rates of the low- and high-pulse durations are identical (both 30.2\%) (IHA Group 4). The non-attainment rates of the fall rate and count are both higher than those of the rise rate and count (IHA Group 5). Generally speaking, the IHA more frequently exceed the RVA upper targets than fall below the lower targets. The results shown in the left-hand part of Figure 3 are a typical example. Such a skew to the high values reveals that the IHA are not normally distributed.

\section{Hydrologic impacts of Chi-Chi diversion weir}

Because the post-construction flow records are not yet available, the hydrologic impacts of Chi-Chi diversion weir are evaluated using the pre-construction flows and the projected demands shown in Figure 2. The mean, standard deviation, range, and non-attainment rate for each of the post-construction parameters are listed in Table III. Significant hydrologic alterations are observed, which are summarized below.

1. Only the monthly means for April to June and September are within the RVA targets, with their non-attainment rates ranging from $55.8 \%$ to $79.1 \%$. The non-attainment rates for the low-flow season are generally higher than 
Table II. IHA before the construction of Chi-Chi diversion weir

\begin{tabular}{|c|c|c|c|c|c|c|c|}
\hline & \multirow[b]{2}{*}{ Mean } & \multirow[b]{2}{*}{ SD } & \multicolumn{2}{|c|}{ Range limits } & \multicolumn{2}{|c|}{ RVA targets } & \multirow[b]{2}{*}{ Non-attainment $(\%)$} \\
\hline & & & Lower & Upper & Lower & Upper & \\
\hline \multicolumn{8}{|l|}{ IHA Group 1} \\
\hline January & 47.5 & 13.6 & 20.9 & 101.3 & 33.9 & 61.1 & 16.3 \\
\hline February & 49.7 & 35.6 & 19.9 & 246.3 & 19.9 & 85.4 & 7.0 \\
\hline March & 63.2 & 52.6 & 27.1 & 339.7 & 27.1 & 115.8 & 9.3 \\
\hline April & 93.6 & 85.1 & 34.4 & 466.6 & 34.4 & 178.7 & 11.6 \\
\hline May & 130.1 & 98.2 & 30.6 & 436.9 & 31.9 & 228.3 & 11.6 \\
\hline June & 269.5 & 158.9 & 36.0 & 615.4 & 110.6 & 428.5 & 39.5 \\
\hline July & 197.8 & 82.2 & 40.2 & 427.3 & 115.6 & 279.9 & 34.9 \\
\hline August & 244.9 & 128.7 & 81.5 & 548.3 & 116.2 & 373.6 & 32.6 \\
\hline September & 252.2 & 172.5 & 45.6 & 867.7 & 79.7 & 424.7 & 18.6 \\
\hline October & 129.5 & 70.5 & 32.2 & 331.3 & 59.0 & 200.0 & 25.6 \\
\hline November & 75.8 & 33.7 & 22.2 & 224.1 & 42.1 & 109.5 & 14.0 \\
\hline December & 54.4 & 12.7 & 18.8 & 86.7 & 41.7 & 67.1 & 23.3 \\
\hline \multicolumn{8}{|l|}{ IHA Group 2} \\
\hline 1-day minimum & 25.7 & 7.4 & 14.5 & 46.4 & 18.3 & 33.1 & 37.2 \\
\hline 3-day minimum & 27.9 & 7.4 & 14.7 & 46.8 & 20.5 & 35.3 & 39.5 \\
\hline 7-day minimum & 30.4 & 7.4 & 15.6 & 47.7 & 23.1 & 37.8 & 32.6 \\
\hline 30-day minimum & 36.2 & 8.7 & 18.5 & 54.7 & 27.6 & 44.9 & 37.2 \\
\hline 90-day minimum & 47.1 & 14.4 & 24.2 & 89.4 & 32.7 & 61.4 & 27.9 \\
\hline 1-day maximum & 2040.2 & 954.8 & 362.0 & 5280.0 & 1085.4 & 2995.0 & 25.6 \\
\hline 3-day maximum & 1343.4 & 580.9 & 326.3 & 2769.3 & 762.5 & 1924.2 & 32.6 \\
\hline 7-day maximum & 895.0 & 395.0 & 280.4 & 2154.3 & 500.0 & 1289.9 & 23.3 \\
\hline 30-day maximum & 445.9 & 172.8 & 160.3 & 1001.5 & 273.1 & 618.7 & 34.9 \\
\hline 90-day maximum & 286.3 & 93.8 & 88.3 & 501.8 & 192.5 & 380.1 & 30.2 \\
\hline \multicolumn{8}{|l|}{ IHA Group 3} \\
\hline Julian date of annual minimum & 81.0 & 85.5 & 14.0 & 363.0 & 14.0 & 166.5 & 9.3 \\
\hline Julian date of annual maximum & 222.5 & 46.0 & 101.0 & 310.0 & 176.5 & 268.6 & 34.9 \\
\hline \multicolumn{8}{|l|}{ IHA Group 4} \\
\hline Low-pulse count & 11.2 & 6.0 & 2.0 & 24.0 & 5.2 & 17.2 & 27.9 \\
\hline High-pulse count & 7.7 & 2.7 & 2.0 & 14.0 & 5.0 & 10.4 & 37.2 \\
\hline Low-pulse duration & 91.5 & 53.7 & 6.0 & 249.0 & 37.8 & 145.2 & 30.2 \\
\hline High-pulse duration & 91.4 & 41.7 & 8.0 & 166.0 & 49.8 & 133.1 & 30.2 \\
\hline \multicolumn{8}{|l|}{ IHA Group 5} \\
\hline Fall rate & -24.9 & 9.9 & -50.0 & -8.1 & -34.7 & -15.0 & 27.9 \\
\hline Rise rate & 33.5 & 14.0 & 9.6 & 74.4 & 19.4 & 47.5 & 16.3 \\
\hline Fall count & 80.1 & 9.6 & 61.0 & 102.0 & 70.5 & 89.8 & 16.3 \\
\hline Rise count & 86.9 & 8.7 & 69.0 & 106.0 & 78.2 & 95.6 & 14.0 \\
\hline
\end{tabular}

those for the high-flow season. The non-attainment rates for the monthly means from November to March are all greater than $90 \%$. The standard deviations of the monthly flows are mostly (10 out of 12) greater than the means, implying the higher fluctuations of the post-construction monthly flows.

2. The means of the annual 1-, 3-, 7-, 30-, and 90-day minima are all below the lower RVA targets with their nonattainment rates being 100\%. The means of the annual 1-, 3-, 7-, and 30-day maxima are within the RVA target ranges with their non-attainment rates slightly greater than the pre-construction values. The mean of the annual 90-day maximum is less than the lower RVA target. The results indicate that the daily, weekly, and monthly maximal flow cycles are only slightly influenced by the diversion weir, whereas all the minimal flow cycles and the seasonal maximal flow cycle are significantly altered by the flow diversion.

3. The mean Julian date of the annual minimum moves from day 81 to the end of a year with a $100 \%$ nonattainment rate. The statistics for the Julian date of the annual maximum are exactly the same as their pre-construction values. This result indicates that the timing of the annual maximum is not altered by the flow diversion because the annual maximum is far greater than the diverted flow. 


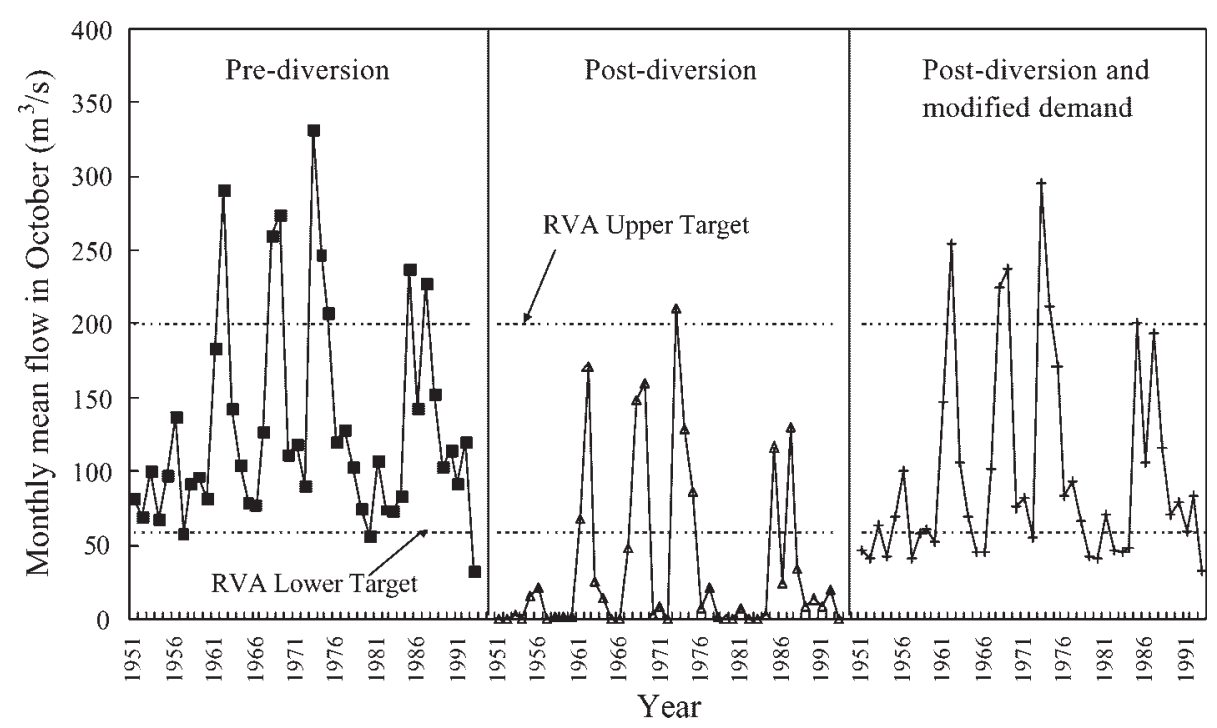

Figure 3. Time series of the monthly mean flow in October for the pre- and post-diversion conditions

4. The means of the low- and high-pulse counts are both within the RVA targets, while the mean of the low-pulse duration is far greater than the upper RVA target and the mean of the high-pulse duration is below the lower RVA target. Most of the daily flows are less than the low pulse $\left(47.8 \mathrm{~m}^{3} / \mathrm{s}\right)$ mainly due to the large magnitude of water diversion, but a few flows exceed the high pulse $\left(143.0 \mathrm{~m}^{3} / \mathrm{s}\right)$ of the pre-construction flows.

5. The non-attainment rates of the four parameters in IHA Group 5 are all increased, despite the fact that the means of the fall and rise rates are both within the RVA target ranges. The means of the fall and rise counts are far below the corresponding lower RVA targets, with their non-attainment rates reaching $97.7 \%$ and $100 \%$, respectively.

In summary, after the weir construction, only 13 out of 32 parameters fall within the RVA target ranges and 30 parameters have non-attainment rates far greater than the corresponding values prior to weir construction. The average non-attainment rate increases from $25.3 \%$ to $73.2 \%$. Figure 3 illustrates the time series of the monthly mean flow in October for the pre- and post-diversion conditions. Generally, the impact of water diversion on the low-flow regime is more significant than on the high-flow regime. For comprehensive water-resources planning, the instream flow requirement (to restore characteristics of the natural flow regime) and flow diversion (to meet the water demand) should be taken into consideration simultaneously. The compromise between the water supplies and instream flow release through a modified diversion scheme is discussed below.

\section{Effects of increasing instream flow release and reducing flow diversion}

In the above analysis, $0.6 \mathrm{~m}^{3} / \mathrm{s}$ is insufficient to maintain the IHA within the RVA target ranges. Wu and Wang (2002) have recommended that $50 \mathrm{~m}^{3} / \mathrm{s}$ is the optimal instream flow for protecting the target species, Sinogastromyzon puliensis, downstream of the Chi-Chi diversion weir. One possible approach for restoration of the natural hydrologic regime is to increase the instream flow release, although this will affect the supplies for other purposes. Four shortage indicators are used herein to evaluate the Chi-Chi diversion weir performance based on the supplydemand relationship. The first indicator is the risk, defined as the probability that the diverted flows are insufficient to meet the established requirements (Hashimoto et al., 1982). Specifically, the risk can be estimated as the ratio of deficit period to the entire study period. The second indicator is the annual mean deficit duration. The third indicator is the deficit ratio, defined as the ratio of total deficit to the total demand over the study period (Cancelliere et al., 1998). The fourth indicator is the annual mean deficit. These indicators encompass the magnitude and duration of the shortage characteristics. 
Table III. IHA after the construction of Chi-Chi diversion weir

\begin{tabular}{|c|c|c|c|c|c|c|c|}
\hline & \multirow[b]{2}{*}{ Mean } & \multirow[b]{2}{*}{ SD } & \multicolumn{2}{|c|}{ Range limits } & \multicolumn{2}{|c|}{ RVA targets } & \multirow[b]{2}{*}{ Non-attainment $(\%)$} \\
\hline & & & Lower & Upper & Lower & Upper & \\
\hline \multicolumn{8}{|l|}{ IHA Group 1} \\
\hline January & 9.4 & 11.2 & 0.6 & 59.4 & 33.9 & 61.1 & 95.4 \\
\hline February & 9.9 & 31.9 & 0.6 & 195.2 & 19.9 & 85.4 & 93.0 \\
\hline March & 16.6 & 46.7 & 0.6 & 276.8 & 27.1 & 115.8 & 90.7 \\
\hline April & 40.1 & 79.9 & 0.6 & 406.4 & 34.4 & 178.7 & 79.1 \\
\hline May & 60.5 & 89.1 & 0.6 & 350.2 & 31.9 & 228.3 & 67.4 \\
\hline June & 154.4 & 144.3 & 0.6 & 485.6 & 110.6 & 428.5 & 55.8 \\
\hline July & 73.9 & 66.4 & 0.6 & 279.6 & 115.6 & 279.9 & 76.7 \\
\hline August & 111.7 & 113.1 & 0.6 & 389.6 & 116.2 & 373.6 & 65.1 \\
\hline September & 120.2 & 158.1 & 0.6 & 708.5 & 79.7 & 424.7 & 60.5 \\
\hline October & 35.3 & 56.4 & 0.6 & 211.2 & 59.0 & 200.0 & 81.4 \\
\hline November & 10.5 & 25.9 & 0.6 & 146.1 & 42.1 & 109.5 & 97.7 \\
\hline December & 1.1 & 1.6 & 0.6 & 8.4 & 41.7 & 67.1 & 100.0 \\
\hline \multicolumn{8}{|l|}{ IHA Group 2} \\
\hline 1-day minimum & 0.6 & 0.0 & 0.6 & 0.6 & 18.3 & 33.1 & 100.0 \\
\hline 3-day minimum & 0.6 & 0.0 & 0.6 & 0.6 & 20.5 & 35.3 & 100.0 \\
\hline 7-day minimum & 0.6 & 0.0 & 0.6 & 0.6 & 23.1 & 37.8 & 100.0 \\
\hline 30-day minimum & 0.7 & 0.3 & 0.6 & 1.8 & 27.6 & 44.9 & 100.0 \\
\hline 90-day minimum & 3.3 & 5.7 & 0.6 & 30.4 & 32.7 & 61.4 & 100.0 \\
\hline 1-day maximum & 1896.0 & 946.9 & 226.4 & 5120.8 & 1085.4 & 2995.0 & 27.9 \\
\hline 3-day maximum & 1200.9 & 574.9 & 190.3 & 2610.1 & 762.5 & 1924.2 & 41.9 \\
\hline 7-day maximum & 753.8 & 391.4 & 144.8 & 1995.0 & 500.0 & 1289.9 & 37.2 \\
\hline 30-day maximum & 309.0 & 166.9 & 40.6 & 842.4 & 273.1 & 618.7 & 39.5 \\
\hline 90-day maximum & 161.1 & 87.1 & 18.1 & 380.0 & 192.5 & 380.1 & 65.1 \\
\hline \multicolumn{8}{|l|}{ IHA Group 3} \\
\hline Julian date of annual minimum & 365.3 & 0.4 & 365.0 & 366.0 & 14.0 & 166.5 & 100.0 \\
\hline Julian date of annual maximum & 222.5 & 46.0 & 101.0 & 310.0 & 176.5 & 268.6 & 34.9 \\
\hline \multicolumn{8}{|l|}{ IHA Group 4} \\
\hline Low-pulse count & 8.9 & 3.1 & 3.0 & 15.0 & 5.2 & 17.2 & 11.6 \\
\hline High-pulse count & 5.6 & 2.7 & 2.0 & 12.0 & 5.0 & 10.4 & 53.5 \\
\hline Low-pulse duration & 295.6 & 40.6 & 205.0 & 361.0 & 37.8 & 145.2 & 100.0 \\
\hline High-pulse duration & 33.7 & 21.6 & 4.0 & 88.0 & 49.8 & 133.1 & 74.4 \\
\hline \multicolumn{8}{|l|}{ IHA Group 5} \\
\hline Fall rate & -16.9 & 8.1 & -38.0 & -2.6 & -34.7 & -15.0 & 44.2 \\
\hline Rise rate & 19.7 & 10.3 & 2.6 & 48.4 & 19.4 & 47.5 & 53.5 \\
\hline Fall count & 35.7 & 14.6 & 12.0 & 70.0 & 70.5 & 89.8 & 100.0 \\
\hline Rise count & 38.7 & 16.5 & 13.0 & 85.0 & 78.2 & 95.6 & 97.7 \\
\hline
\end{tabular}

The results of increasing instream flow release are summarized below.

For IHA Group 1. (monthly mean flow), Figure 4 shows that increasing the instream flow release to $45 \mathrm{~m}^{3} / \mathrm{s} \mathrm{sig-}$ nificantly reduces the non-attainment rates of the low-flow season (November to May). Increasing the instream flow release further to 60 and $80 \mathrm{~m}^{3} / \mathrm{s}$ reduces the non-attainment rates of October and September, respectively. The non-attainment rates of June to August are not influenced because their lower RVA targets are all greater than $80 \mathrm{~m}^{3} / \mathrm{s}$.

For IHA Group 2. (annual extremes), increasing the instream flow release to $35 \mathrm{~m}^{3} / \mathrm{s}$ effectively reduces the nonattainment rates of the multi-day annual minimum. However, the non-attainment rates of the multi-day annual maximum are not affected.

For IHA Group 3. (timing of annual extremes), increasing the instream flow release to $40 \mathrm{~m}^{3} / \mathrm{s}$ reduces the nonattainment rate of the annual-minimum Julian date to the pre-construction value, $9.3 \%$. The non-attainment rate of the annual-maximum Julian date is not affected even when the instream flow release increases to $80 \mathrm{~m}^{3} / \mathrm{s}$. 


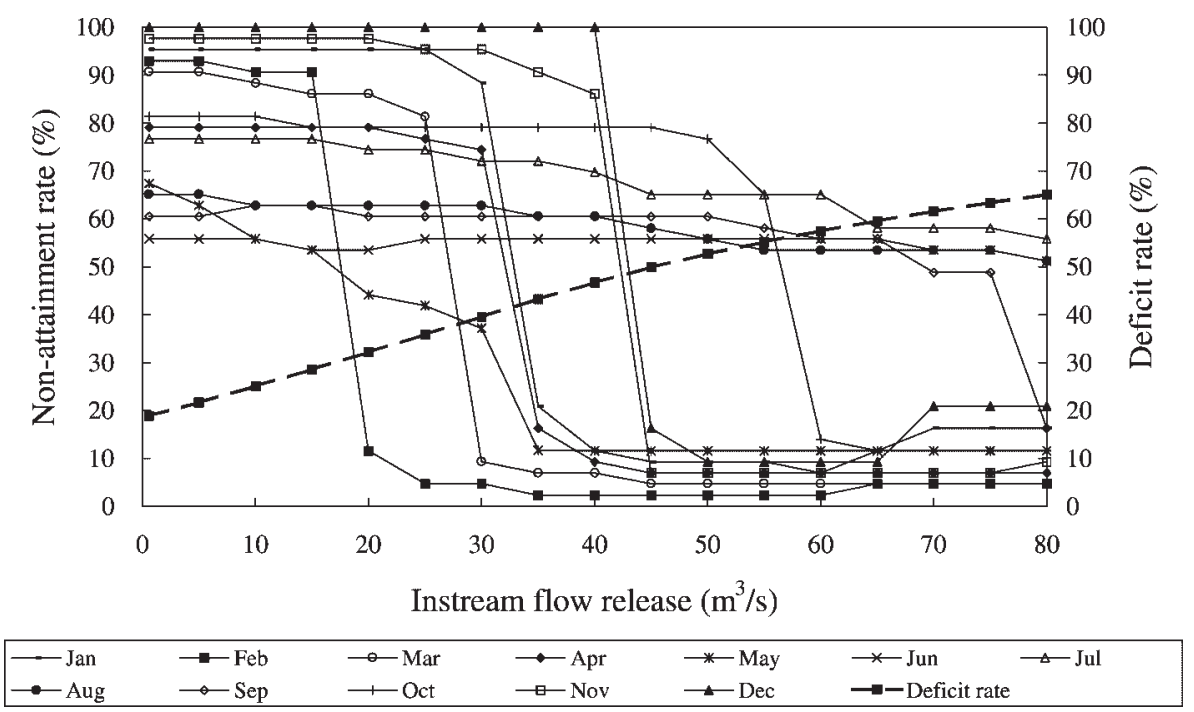

Figure 4. Variations with the instream flow release of the non-attainment rate for IHA Group 1 (monthly mean flow) and the deficit rate

For IHA Group 4. (frequency and duration of high and low pulses), increasing the instream flow release to $50 \mathrm{~m}^{3} / \mathrm{s}$ effectively reduces the non-attainment rate of the low-pulse duration, but the non-attainment rate of the low-pulse count is increased. Nevertheless, the non-attainment rate of $27.9 \%$ remains identical to the pre-construction value, implying that the low-pulse frequency is unlikely to become inferior. The non-attainment rates of the high-pulse count and duration are not affected by increasing the instream flow release.

For IHA Group 5. (rate and frequency of flow changes), no significant alterations are observed with the increase of instream flow release. The non-attainment rates of the fall and rise counts slightly decrease when the instream flow release is increased to $45 \mathrm{~m}^{3} / \mathrm{s}$.

Only one shortage indicator is shown in Figure 4, but all shortage indicators increase with the increasing instream flow release. The deficit ratio, annual mean deficit, risk, and annual mean deficit duration are increased from 18.9 to $65.1 \%, 592.3$ to $2041.0 \mathrm{~m}^{3} /$ year, 61.0 to $85.9 \%$, and 222.7 to 313.9 days/year, respectively, as the instream flow release increases from 0.6 to $80 \mathrm{~m}^{3} / \mathrm{s}$. A common trend can be found for the low-flow characteristics of all IHA Groups. The monthly means for the low-flow season, multi-day annual minimum, annual-minimum Julian date, and low-pulse duration are sensitive to the flow diversion. Diverting water from the river affects the natural low-flow regime more substantially than the high-flow one. However, the low-flow characteristics are easier to restore to the natural conditions if the instream flow release is increased to a certain level. The above analysis indicates that the increase of instream flow release to approximately $30-50 \mathrm{~m}^{3} / \mathrm{s}$ can effectively restore most of the IHA to the pre-diversion condition.

On the other hand, the fluctuations of the natural daily flows often result in unstable water supplies to various end users. When the natural flows in the river are insufficient for the established goals, some auxiliary sources (such as subsurface water resources, or interconnection with neighbouring systems) are required as supply-management measures to mitigate the negative impacts caused by water shortage. In addition to the supply-phase mitigation, the demand-management measures, such as demand reduction, water conservation, and temporary water restriction, are also crucial for drought prevention (AWWA, 2002). Herein, the demand reduction is taken as an alternative approach to restoring the altered hydrologic regime to the natural condition. The projected demand (shown in Figure 2) is reduced by a constant percentage for all months. The instream flow release is taken to be $40 \mathrm{~m}^{3} / \mathrm{s}$ because it is shown above that this amount of water can satisfactorily restore the low-flow regime. The restored non-attainment rates for the IHA Groups 1-5 are summarized below.

For IHA Group 1. (monthly mean flow), Figure 5 shows that the non-attainment rates of the low-flow months (January to May) do not vary significantly and the values are all below $20 \%$ because of the 


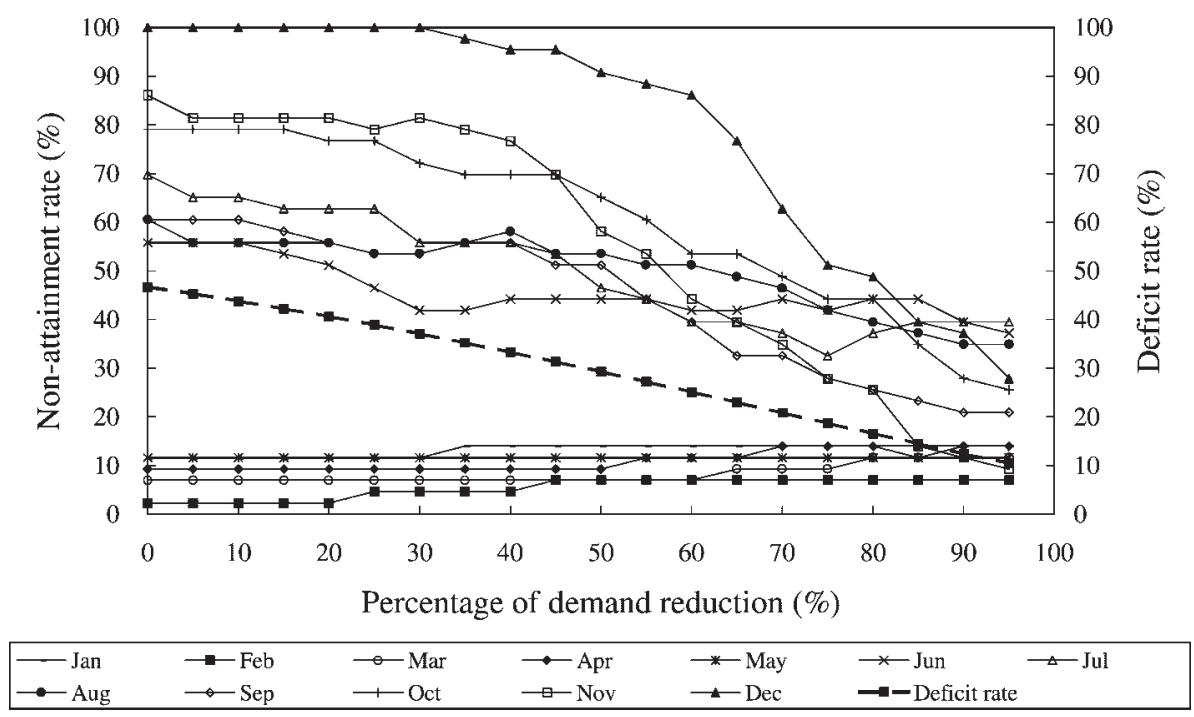

Figure 5. Variations with the demand reduction of the non-attainment rate for IHA Group 1 (monthly mean flow) and the deficit rate

instream flow release. The non-attainment rates of October to December are higher than those of other months because the instream flow release is insufficient for the lower RVA targets. The non-attainment rates of these three months start to decrease as the demand is reduced by $30 \%$.

For IHA Group 2. (annual extremes), the non-attainment rates of the annual minima do not vary significantly with demand reduction. The non-attainment rate of only the 90-day minimum slightly increases with demand reduction, while its mean value is still within the RVA target ranges.

For IHA Group 3. (timing of annual extremes), demand reduction has almost no effect on the non-attainment rates of the annual-minimum and annual-maximum Julian dates, primarily due to the sufficient instream flow release. The non-attainment rates of the annual-minimum and annual-maximum Julian dates are nearly identical with the pre-construction values.

For IHA Group 4. (frequency and duration of high and low pulses), the non-attainment rate of the low-pulse count is below the pre-construction value. The non-attainment rate of the low-pulse duration starts to decrease when the demand is reduced by $30 \%$. The non-attainment rates of the high-pulse count and duration, decreasing slightly with demand reduction, are greater than the pre-construction values.

For IHA Group 5. (rate and frequency of flow changes), non-attainment rates of the rise and fall counts are lowered significantly when the demand is reduced by $60 \%$ or more, although still beyond the RVA target ranges. The reduction of demand by $85 \%$ or more will make the mean rise and fall counts hit the RVA targets.

It is demonstrated that all the shortage indicators decrease with the reduction of demand, although only the deficit rate is shown in Figure 5. From the above, we know that increasing the instream flow release is likely to restore the characteristics of the low-flow regime. Reducing the demand further improves the high-flow regime. However, restoration of the natural flow regime is achieved only at the cost of reducing water supplies. The reduced water supplies violate the purpose of Chi-Chi diversion weir. A modified diversion scheme is proposed in the following section.

\section{Effect of modified diversion scheme}

The effect of a modified diversion scheme is investigated in this section. The water diversions for January to December are reduced to $20 \%, 20 \%, 30 \%, 60 \%, 60 \%, 50 \%, 50 \%, 50 \%, 50 \%, 30 \%, 20 \%$, and $10 \%$ of the projected 
Table IV. IHA for the modified diversion scheme

\begin{tabular}{|c|c|c|c|c|c|c|c|}
\hline & \multirow[b]{2}{*}{ Mean } & \multirow[b]{2}{*}{ SD } & \multicolumn{2}{|c|}{ Range limits } & \multicolumn{2}{|c|}{ RVA targets } & \multirow[b]{2}{*}{ Non-attainment (\%) } \\
\hline & & & Lower & Upper & Lower & Upper & \\
\hline \multicolumn{8}{|l|}{ IHA Group 1} \\
\hline January & 43.0 & 11.7 & 20.9 & 92.9 & 33.9 & 61.1 & 14.0 \\
\hline February & 45.8 & 33.7 & 19.9 & 236.1 & 19.9 & 85.4 & 7.0 \\
\hline March & 55.1 & 48.5 & 27.0 & 320.9 & 27.1 & 115.8 & 9.3 \\
\hline April & 74.3 & 77.3 & 34.3 & 437.3 & 34.4 & 178.7 & 9.3 \\
\hline May & 96.9 & 88.5 & 30.5 & 384.9 & 31.9 & 228.3 & 11.6 \\
\hline June & 212.5 & 150.2 & 29.7 & 550.5 & 110.6 & 428.5 & 44.2 \\
\hline July & 133.6 & 73.1 & 38.1 & 351.9 & 115.6 & 279.9 & 46.5 \\
\hline August & 174.5 & 121.6 & 40.4 & 468.9 & 116.2 & 373.6 & 53.5 \\
\hline September & 182.3 & 166.4 & 37.7 & 788.1 & 79.7 & 424.7 & 51.2 \\
\hline October & 97.1 & 67.4 & 32.2 & 295.0 & 59.0 & 200.0 & 48.8 \\
\hline November & 61.9 & 31.6 & 22.2 & 208.5 & 42.1 & 109.5 & 25.6 \\
\hline December & 48.4 & 10.8 & 18.8 & 78.8 & 41.7 & 67.1 & 37.2 \\
\hline \multicolumn{8}{|l|}{ IHA Group 2} \\
\hline 1-day minimum & 25.5 & 7.1 & 14.5 & 40.0 & 18.3 & 33.1 & 37.2 \\
\hline 3-day minimum & 27.7 & 7.0 & 14.7 & 40.0 & 20.5 & 35.3 & 39.5 \\
\hline 7-day minimum & 29.9 & 6.7 & 15.6 & 40.0 & 23.1 & 37.8 & 30.2 \\
\hline 30-day minimum & 34.1 & 6.4 & 18.5 & 44.1 & 27.6 & 44.9 & 16.3 \\
\hline 90-day minimum & 40.9 & 10.3 & 24.2 & 77.0 & 32.7 & 61.4 & 18.6 \\
\hline 1-day maximum & 1969.3 & 951.3 & 294.2 & 5200.4 & 1085.4 & 2995.0 & 23.3 \\
\hline 3-day maximum & 1272.8 & 578.1 & 258.5 & 2689.7 & 762.5 & 1924.2 & 32.6 \\
\hline 7-day maximum & 826.2 & 392.4 & 212.6 & 2074.7 & 500.0 & 1289.9 & 30.2 \\
\hline 30-day maximum & 378.3 & 168.9 & 96.4 & 922.0 & 273.1 & 618.7 & 39.5 \\
\hline 90-day maximum & 222.6 & 89.1 & 61.7 & 430.5 & 192.5 & 380.1 & 41.9 \\
\hline \multicolumn{8}{|l|}{ IHA Group 3} \\
\hline Julian date of annual minimum & 86.1 & 89.7 & 14.0 & 363.0 & 14.0 & 166.5 & 11.6 \\
\hline Julian date of annual maximum & 222.5 & 46.0 & 101.0 & 310.0 & 176.5 & 268.6 & 34.9 \\
\hline \multicolumn{8}{|l|}{ IHA Group 4} \\
\hline Low-pulse count & 13.4 & 4.5 & 5.0 & 25.0 & 5.2 & 17.2 & 11.6 \\
\hline High-pulse count & 6.8 & 3.1 & 2.0 & 13.0 & 5.0 & 10.4 & 53.5 \\
\hline Low-pulse duration & 198.2 & 74.3 & 45.0 & 352.0 & 37.8 & 145.2 & 72.1 \\
\hline High-pulse duration & 52.2 & 28.6 & 4.0 & 120.0 & 49.8 & 133.1 & 46.5 \\
\hline \multicolumn{8}{|l|}{ IHA Group 5} \\
\hline Fall rate & -20.7 & 9.1 & -43.5 & -4.7 & -34.7 & -15.0 & 37.2 \\
\hline Rise rate & 26.2 & 12.6 & 5.3 & 63.4 & 19.4 & 47.5 & 37.2 \\
\hline Fall count & 63.9 & 8.7 & 46.0 & 81.0 & 70.5 & 89.8 & 81.4 \\
\hline Rise count & 68.9 & 9.2 & 50.0 & 93.0 & 78.2 & 95.6 & 86.1 \\
\hline
\end{tabular}

demands, respectively (shown in Figure 2). These reduction percentages are determined by comparing the monthly mean flows, projected demands, instream flow release, and results of the above analysis. For instance, the average flow available for diversion in December is $14.4 \mathrm{~m}^{3} / \mathrm{s}$ (pre-diversion mean flow, $54.4 \mathrm{~m}^{3} / \mathrm{s}$, minus the instream flow release, $40 \mathrm{~m}^{3} / \mathrm{s}$ ), which is approximately $18 \%$ of the projected demand, $79 \mathrm{~m}^{3} / \mathrm{s}$. Also taking into consideration the non-attainment rate, we select $10 \%$ as the percentage of demand reduction in December because a desirable nonattainment rate can be achieved. The instream flow release is taken to be $40 \mathrm{~m}^{3} / \mathrm{s}$ as stated previously. The modified annual demand is $1266 \mathrm{Mm}^{3}, 41 \%$ of the projected annual demand. The IHA for the modified diversion scheme are given in Table IV. The monthly mean flow in October for the modified scheme is also shown in Figure 3 for comparison. Significant improvement is demonstrated in Table IV and Figure 3. The non-attainment rates of all the IHA are reduced. Only three IHA, i.e. the low-pulse duration, and fall and rise counts, are beyond the RVA targets. The non-attainment rates of the remaining 29 IHA are all below 53.5\%, with an average of $31.0 \%$, which is only slightly greater than the pre-construction value of $25.3 \%$. The non-attainment rates of the low-pulse duration, 
Table V. Shortage characteristics for the projected and modified diversion scheme

\begin{tabular}{lcr}
\hline & Projected diversion scheme & Modified diversion scheme \\
\hline Annual water demand $\left(10^{6} \mathrm{~m}^{3} /\right.$ year $)$ & 3080.8 & 1266.0 \\
Risk $(\%)$ & 61.0 & 44.9 \\
Annual mean deficit duration (days/year) & 222.7 & 163.9 \\
Deficit rate $(\%)$ & 18.9 & 21.6 \\
Annual mean deficit $\left(10^{6} \mathrm{~m}^{3} /\right.$ year $)$ & 592.3 & 278.1 \\
\hline
\end{tabular}

and the fall and rise counts are reduced from 100,100 , and $97.7 \%$ to $72.1,81.4$, and $86.1 \%$, respectively. The average non-attainment rate of 32 parameters is $35.6 \%$, which is considerably lower than the post-construction value, $73.2 \%$, and is much closer to the pre-construction value of $25.3 \%$. The shortage characteristics of the original projected demand (with an instream flow release of $0.6 \mathrm{~m}^{3} / \mathrm{s}$ ) and the modified diversion scheme (with an instream flow release of $40 \mathrm{~m}^{3} / \mathrm{s}$ ) are provided in Table V. The water supply for the modified diversion scheme is significantly reduced, but a more stable water supply is achieved. The risk, annual mean deficit duration, and annual mean deficit are reduced from 61.0 to $44.9 \%$, from 222.7 to 163.9 days/year, and from 592.3 to $278.1 \mathrm{Mm}^{3} /$ year, respectively. Only the deficit rate is slightly increased from 18.9 to $21.6 \%$. The modified diversion scheme with an instream flow release of $40 \mathrm{~m}^{3} / \mathrm{s}$ has considerable potential to restore the altered hydrologic regime to the natural condition.

\section{CONCLUDING REMARKS}

1. Substantial inter-annual variations in natural flow characteristics were present in the midstream Chou-Shui Creek, Taiwan. An average non-attainment rate of $25.3 \%$ was observed for the 32 hydrologic parameters prior to the weir construction.

2. The current instream flow release $\left(0.6 \mathrm{~m}^{3} / \mathrm{s}\right)$ causes great impacts to the natural hydrologic regime. Only 13 of 32 hydrologic parameters, primarily high-flow characteristics, fall within the RVA targets. The average nonattainment rate of the post-construction parameters reaches $73.2 \%$. The results indicate that the Chi-Chi diversion weir has a greater influence on the low-flow than on the high-flow regime.

3. Various instream flow releases and demand reductions are tested to assess their hydrologic effects. Increasing the instream flow release to $40 \mathrm{~m}^{3} / \mathrm{s}$ makes most of the IHAs of the low-flow regime fall within the RVA target ranges. A further reduction of the projected demand by $30 \%$ or greater substantially reduces the non-attainment rates of the high-flow regime, although this reduces water supplies.

4. Based on the results of this study, a modified diversion scheme (shown in Figure 2) together with an instream flow release of $40 \mathrm{~m}^{3} / \mathrm{s}$ is recommended as an alternative to alleviate the altered flow regime. Through this modification, only three hydrologic parameters, i.e. the low-pulse duration, and the fall and rise counts, are beyond the RVA targets. The average non-attainment rate is reduced to $35.6 \%$, which is much closer to the pre-construction value of $25.3 \%$.

Construction and operation of the diversion weir, with the aim of providing water resources for municipal, industrial, and agricultural purposes, will cause considerable hydrologic alterations. With the RVA, the effects on the hydrologic regime of the weir construction can be assessed, and the targets for river management can be established. Potential restoration to the pre-construction condition can be achieved by increasing the instream flow release and/or reducing the water diversion. The proposed diversion scheme leads to a reduced but more stable water supply. The aquatic environment and ecosystem can be better sustained through such modification. This study offers useful information to the water resources agency, the Central Water Resources Bureau, for re-evaluating the current diversion scheme. The reduction of water supplies can be mitigated through joint operation of Chi-Chi diversion weir and the proposed Hushan-Hunan reservoir, although further studies are still needed. 


\section{REFERENCES}

AWWA. 2002. Drought Management Handbook. American Water Works Association: Denver, Colorado.

Benjamin L, VanKirk RW. 1999. Assessing instream flows and reservoir operations of an Eastern Idaho River. Journal of the American Water Resources Association 35: 899-909.

Cancelliere A, Ancarani A, Rossi G. 1998. Susceptibility of water supply reservoirs to drought conditions. Journal of Hydrologic Engineering 3: $140-148$

Cardwell H, Jager HI, Sale MJ. 1996. Designing instream flows to satisfy fish and human water needs. Journal of Water Resources Planning and Management 122: 356-363.

Central Water Resources Bureau. 2002. 2002 Projected Demands for Chi-Chi Diversion Weir. Water Resources Agency: Taiwan (in Chinese),

Cowell CM, Stoudt RT. 2002. Dam-induced modifications to upper Allegheny River streamflow patterns and their biodiversity implications. Journal of the American Water Resources Association 38: 187-196.

Flug M, Seitz HLH, Scott JF. 2000. Multicriteria decision analysis applied to Glen Canyon dam. Journal of Water Resources Planning and Management 126: 270-276.

Hashimoto H, Stedinger JR, Loucks DP. 1982. Reliability, resiliency, and vulnerability criteria for water resources system performance evaluation. Water Resources Research 18: 14-20.

Jowett IG. 1997. Instream flow methods: a comparison of approaches. Regulated Rivers: Research and Management 13: $115-127$.

Milhous RT, Updike MA, Schneider DM. 1989. Physical Habitat Simulation System Reference Manual-Version II. Instream Flow Information Paper No. 26. Biological Report 89(16). US Fish and Wildlife Service: Washington, DC.

NRC (National Research Council). 1992. Restoration of Aquatic Systems: Science, Technology, and Public Policy. National Academy Press: Washington, DC.

Reiser DW, Wesche TA, Estes C. 1989. Status of instream flow legislation and practices in North America. Fisheries 14: 22-29.

Richter BD, Baumgartner JV, Powell J, Braun DP. 1996. A method for assessing hydrologic alteration within ecosystems. Conservation Biology 10: 1163-1174.

Richter BD, Baumgartner JV, Wigington R, Braun DP. 1997. How much water does a river need. Freshwater Biology 37: 231-249.

Sale MJ, Brill ED, Herricks EE. 1982. An approach to optimizing reservoir operation for downstream aquatic resources. Water Resources Research 18: 705-712.

Smith SE, Buttner G, Szilagyi F, Horvath L, Aufmuth J. 2000. Environmental impacts of river diversion: Gabcikovo Barrage System. Journal of Water Resources Planning and Management 126: 138-145.

TESRC (Taiwan Endemic Species Research Center). 1995. Fishes in Nantou, Taiwan. Nantou: Taiwan (in Chinese).

TESRC (Taiwan Endemic Species Research Center). 1996. Taiwan Endemic Species_Fish and Wildlife. Nantou: Taiwan (in Chinese).

Wang S, Lin LJ. 1998. Chi-Chi common diversion weir project. Proceedings of the 9 th Hydraulic Engineering Conference, Chung-Li, Taiwan; D1-D13 (in Chinese).

Wu FC, Lee KS. 1998. Assessment of instream flow for Chi-Chi common diversion weir. Proceedings of Water Resources Management Conference, Taipei, Taiwan; 216-237 (in Chinese).

Wu FC, Wang CF. 2002. Effect of flow-related substrate alteration on physical habitat: a case study of the endemic river loach Sinogastromyzon puliensis (Cypriniformes, Homalopteridae) downstream of Chi-Chi diversion weir, Chou-Shui Creek, Taiwan. River Research and Applications 18: 155-169. 